\title{
Advertise With Social Discourse, as a Brand Positioning Technique: The Focuse on Consumers Advertising
}

\author{
Aivars Gabriel Helde ${ }^{a}$
}

\begin{abstract}
This study examines the nature of the social discourse of advertising used as a brand positioning discourse. The focus is on consumer advertising, which is directed toward the promotion of some product or service to the general public. This paper aimed at analyzing some different commercial advertisements (product/non-product ads) to investigate the intentions and techniques of consumer product companies to reach more consumers and sell more products. Norman Fairclough's 3-D model and Kress and Van Leeuwen's grammar of visual design were used to analyze the data for professionals, but we are pointed on using stereotypes. When we consider gender stereotypes, we look at notions about the supposedly traditional behaviors of men and women and the characteristics and standards of these behaviors, as grounded in our culture and society. In addition, this study provides analyses of some ads, using different ways of interpretations. All materials are taken from Latvian media.
\end{abstract}

\section{Keywords}

Social discourse analysis, branding, advertising

As the elements of the marketing program come together to create the complete offering, marketers must also consider how the marketing program will be used to create effective branding and positioning.

While the concept of a brand may seen relatively simple to understand, branding strategy can actually be quite complex. From a technical point of view, a brand is a combination of name, symbol, term, or design that identifies a specific product. Brand have two parts: the brand name and the brand mark (Ferrell and Hartline [2011] 2014). The brand name is the part of a brand that can be spoken, including words, letters, and numbers (Laima, KDF, 7-up). The brand mark - which includes symbols, figures, or a design is the part of brand that cannot be spoken (Nike's swoosh). Jenni Romaniuk, the professor from
Ehrenberg-Bass Institute says:

Distinctive assets are the branding elements that uniquely identify the brand across the vast majority of category buyers, such as the Nike Swoosh or red and yellow M\&Ms. The opportunity and challenge of distinctive assets is that potential assets can come from a wide source of possibilities, from colors, fonts, advertising style, celebrities, characters or logos-just to name a few .

While these technical aspects of branding are

aRiga International School of Economics and Business Administration (RISEBA), Latvia

\section{Correspondent Author:}

Aivars Gabriel Helde, Meža iela3, Rīga, LV-1048

E-mail: awhelds1@inbox.lv 
important, branding strategy involves much more than developing a clever brand name or unique brand mark. Good brands are those that immediately come to mind when a customer has a problem to be solved or a need to be fulfilled. So it is "the battle for your mind" (Ries and Trout 2001).

However, for most people, advertising is something to encourage or persuade them to buy a special product. But advertisings do not only serve this purpose, they "also amuse, inform, misinform, worry, though it may be argued that these functions are all in the service of the main function" (Cook 1992). Considering the other side, there are non-product advertisements as well that without promoting any products only advocate a change in behavior. The non-product ads are used in different campaigns and they show the effects of not adopting the advocated behavior. "Ads may not always be obliged to refer to a product, but they are still obliged to refer, however obliquely, to a change of behavior" (Cook 1992).

Today is very modern to use the third possibility-both to combine these techniques and promote product using different cultural and behavioral stereotypes. The aim of these advertisements is not to change some one habit of behavior but on the contrary—seek to maintain or strengthen these habits.

Advertisings have been involved with our everyday lives: It is mirroring of society and it is transmitting of meaning and message, and it is social significance have lead people to consider it as a discourse type. Cook (1992) also remarked that "Advertising is not a remote and specialized discourse, but a prominent discourse type in contemporary society”.

Discourse has been described by Gee ([1999] 2005) as "language (oral or written) in use with more socio-politically oriented meaning”. Fairclough ([1989] 1995) went further and defined it as "just a particular form of social practice" that in its center power and ideology influence and interact with one another. In other words, discourse constitutes social practice and is at the same time constituted by it (Wodak 1999).

Intertextuality has been described as texts (which) are recognized in terms of their dependence on other relevant texts. Essentially, it amounts to the relationship between text and the various language or signifying practices of a culture and its relation to those texts which articulate for it the possibilities of that culture. Therefore, one reason for the success of an advertisement or commercial may well be the underlying relationship between its presentation and a literary association familiar to the target audience.

"Standard ad messaging and conventional creative executions and placement are rapidly becoming outmoded. To win consumer's attention and trust, marketers must think less about what advertising says to its targets and more about what it does for them" (Rayport 2013).

\section{STATEMENT OF THE PROBLEM AND PURPOSE}

Many studies of advertising do separate out components of ads, concentrate on one or a few and ignore the others. There are some theories traditionally used as Fairclough-3D, Krees and Van Leeuwen's visual grammar, very good for students and researchers but not useable for customers.

The successful ads are described in their three basic parameters: strategy, creativity, and fabrication. The strategy: specific target selection, the target audience's choice, report creation, and media planning, very understandable and clear. Describing advertising as discourse is both more complex and more difficult than any of these approaches. It must be come in mind, then, that there is a danger of dilution in analysis which attempts to tackle too much.

Professionals advise marketers to approach this medium as a landscape composed of four domains: the public sphere, where we move from one place or 
activity to other, both online and off; the social sphere, where we interact with and relate to one another; the tribal sphere, where web afiliate with groups to define or express our identity; and the psychological sphere, where we connect language with specific thoughts and feelings (Rayport and Jaworski 2004). This study will try to focus on local Latvian ads with social discourse as principle of a brand communication with customer, based on customer cultural habits and expectations.

\section{CULTURE AND COMMUNICATION}

Because the United States is the birthplace of marketing and advertising theory and techniques, American cultural assumptions are at the root of philosophies of how advertising works, not only in the United States but also in other parts of the world. If it is necessary to understand how advertising works and is influenced by culture, in this case, we will firstly have to learn how communication works.

All living human beings communicate through sounds, speech, movements, gestures, and language. Communication involves many human activities, speaking, listening, reading, writing, viewing, and creating images. How people communicate is based on cultural conventions that are adhered to in interacting with other people, in producing and sending messages and in interpreting messages. (Marieke de Mooji 2014)

Social advertising, like social marketing, in the Baltic states are relatively new academic environment even a little conscious, but in practice has accumulated a certain experience in this form of advertising. The public should be financially well-developed, so that the country can develop a good social ad. Than social problems are no longer updated, presented, and resolved on the basis that it is cold outside, so there will be fewer homeless because they are cold, but thinking about the effectiveness of visual expression in ways to attract public attention, legislators and officials consideration to ways and possibilities of finding shelter for these homeless people warm. Social marketing is based on the public interest and the needs of the desire to improve the lives of members of the public quality. There is an opinion that social marketing professionals have to deal with the problems, the threats posed by commercial advertising. This point of view is based on the belief that commercial marketing is an activity with which the consumer is under pressure to buy unnecessary things in reality, thus depreciating the spiritual and intellectual values. Therefore, to achieve the objective, namely, to change the commercial advertising audience and each of us to advertising attitude and behavior, it brings social advertising need to be particularly eye-catching. Eye-catching methods are not different from those which are used in commercial marketing. You can use popular personalities, opinion leaders, etc. But social advertising should be based on true facts, it can not lie, exaggerate, or embellish any case, the product, process, or tendency. Social advertising impact also depends on the style of advertising, ability to reach the target group. Specialists say that ineffective social advertising is if:

(1) It is preachy character, for example, if you care about your child... All parents feel that they care about their children, even if they are not, they think that they care about, and such a preachy tone can cause a backlash;

(2) Advertiser complains accused, for example, pointing out where you were at the time when something happened;

(3) Are used in empty clichés and general diplomatic, welcome messages, such as No drugs! The following messages are not intended for the target audience, which meant for a specific ad, they are absolutely indifferent to such an appeal.

More likely to draw public and direct attention to specific target groups are: 
(1) To look at the problem completely unusual manner, contrary to the usual. The audience stopped working simple things;

(2) Causing strong emotions (fear, surprise, and sympathy);

(3) Provoking conflict as a result of the man himself comes to the desired conclusion. It is observed the conclusion that man is supposedly committed himself, his mind is more valuable and important than what he said in front of;

(4) Revealing the naked truth-revealing facts that the most likely public knows hardly anyone;

(5) Shocking.

\section{Hidden Commerce Ad}

Attention is drawn to the fact that even under ads are considered to be social, you can hide a "Trojan horse"-hidden commerce ad. It occurs when the advertising is almost gave the social problem and to address it is offered a particular product, a particular brand. For example, an advertisement for the need to use a condom, thereby protecting themselves from unwanted pregnancy or disease. Advertising slogan—use a condom! However, the ad appears in a particular brand. These ads supposedly reflect a social problem, but the goal still is to promote a specific product sales rise. This hidden marketing gains popularity, especially in countries with a high standard of living. For example, an advertisement for the popular drink Coca-Cola, is reflected in values such as friendship, love, but the main goal is still to sell the product. It would be useful to think about or publicizing seemingly innocent social advertising, failure to comply with any commercial interests. Even if initially it does not seem, however, think about the ads, which invites us to vaccination, such as the flu. Part of the cost of the vaccine, we are paying the same and the second part-we ourselves, only through the state, because the state pays for immunizations tax money. Winner is the pharmaceutical business. This begs the question — are social ad, offering to solve the problems of the consequences is really a non-commercial?

\section{ENTREPRENEUR SOCIAL RESPONSIBILITY}

Not rarely companies use a form of marketing that particular brand positioning as a socially responsible, strategically linking a company of charity. This form of marketing is based on the belief that charity makes it possible to promote business. Trademark is strategically aligned with charity events, and it is just a neat marketing trick, it certainly enhances the brand value and enhances the reputation of the company into the society. The implementation of such marketing policy holder has not only the company but also for the customer. Consumers can get two benefits-buying a product and supporting charity events organized by the relevant product manufacturer or distributor. The consumer feels delighted done a good job without spending extra money. Undoubtedly, this form of marketing is complex, because it has successfully connected two types of interest-social and commercial. A successful result will only be possible if the charity and the commercial interests share the same territory, namely, the company's management to believe that their business activities, they can also contribute to a positive development of society.

\section{SOCIAL RESPONSIBILITY AND ADVERTISING}

The traditional view of marketing holds that ethics and social responsibility are good supplements to business activities but may not be essential.

Today we can see that ethical behavior can not only enhance a company's reputation, but also contribute significantly to its bottom line (Maignan et al. N.d.; Nooyi 2008).

"Social responsibility is a broad concept that relates to an organization's obligations to maximize its positive impact on society while minimizing its 
negative impact. Social responsibility consists of four dimensions: economic, legal, ethical and philanthropic" (Carroll 1991).

If a company tries to ignore a social responsibility - it can destroy customers' trust to the company. In response to customers' demands, along with the threat of increased regulations, firms increasingly incorporate ethics and social responsibility into the strategic marketing plan.

By other way, firms pretend to be social responsible but really in the way, how it turns out this is just a marketing trick. As de Bono said, it is not easy to realize where is the line between social responsibility and pretending to be socially responsible.

Accordingly, ads can be explained using a meaningful discourse. One of the methods could be Hall (1973)—“The theory of encoding/decoding”.

The term encoding describes the process of the production of the message, while decoding is about the reception and how the receivers make sense out of the encoded message. Hall said, "In the advertising discourse, for example, we might say that there is almost no 'purely denotative' communication. Every visual sign in advertising 'connotes' a quality, situation, value or inference which is present as an implication or implied meaning, depending on the connotational reference” (Hall 1973).

This theory could be used to analyze the type of discourse to clearly realised the implicit ideologies what are behind this ads.

For better analyze images as researchers, we can use method described by Fairclough ([1989] 1995) and later developed by Kress and Van Leeuwen (1996), well known as "visual grammar".

"We take the view that language and visual communication both realize the same more fundamental and far-reaching systems of meaning that constitute our cultures, but that each does so by means of its own specific forms, and independently" (Kress and Van Leeuwen 1996).

Fairclough developed three-dimensional boxes.
The inner box presents the text, the middle box-the discourse practice, and the outer one presents the socio-cultural practice. In printed advertisement, these two made multimodal message.

Kress and Van Leewen define two components for visual discourse: represented participants and interacitve participants. By represented participants, they mean people or things that are mapped on an image, while by interactive participants, they mean producers and viewers. Among all these participants exists relations. The relations between the represented participants can be considered as syntactic, between the represented and interactive participants as semantic and between interactive participants as pragmatic.

However, even though people mindlessly absorb the messages promulgated constantly by advertisements, and although these may have some subliminal effects on behavior, we accept media images, by and large, only if they suit our already established preferences. It is more accurate to say that advertising produces images that reinforce lifestyle models. Advertisers are not innovators. They are more intent on reinforcing lifestyle behaviors than in spreading commercially risky innovations. In this sense, advertisements are not in themselves disruptive of the value systems of the cultural mainstream; rather, they reflect shifts already present in popular culture. And if they are really psychologically effective, it is primarily because they tap into deep-ingrained mythical and metaphorical structures of the mind.

\section{SOCIAL ADVERTISING IN LATVIA}

After the collapse of the Soviet Union, rapidly developed the idea of the free market, and became acute competition, which is before the national market economy was unfamiliar. It is essential that at the beginning of 90s, psychologists observed that throughout the former Soviet Union, people were very easily influenced, people were very vulnerable and 
subject to a specific impact. This trend led to the so-called shock-cultural phenomenon that is observed a drastic change-changed values. Society was vulnerable, because it had not yet developed a new scale of values. In such an environment, it began to develop commercial activities and also the Commercial advertising. It could be argued that the process resembled a game without rules. The law on advertising was not adopted until December 20, 1999. In such an environment, it could not and did not develop social advertising. In the foreground, it was existential survival problem. Commercial advertising was also built quite brutally, creating the illusion of happiness for various goods and products appearance. More than 10 years later, commercial advertising was formed by a kind of jungle or the Wild West of the principle. By the time, it took a more prominent not only in the media but also to the environment. Only in the last 10 years, it has occurred in the social advertising. The author must admit that it not only fulfilled its own direct role but also to fight for place in an environment that is already oversaturated with commercial advertising. So often irony causes inscriptions "Free place your ad"... In addition, the problem of social advertising is the fact that these ads usually focuse on topics that are not popular with the public - they are often trying to ignore them, because they do not get feelings of happiness, unlike commercial advertising. Despite this, in recent years, Latvian regularly made a very effective social advertising with bright creative performance. They attract attention, suggesting some perhaps shocking, someone like that, but the most important does not leave you indifferent. In many European Union (EU) countries, social advertising are divided into special either-hours into the electronic media. The fact that the Latvian legislation has no definition of social advertising status, according to the situation. As a result, social advertising customers pay for advertising in the media as much as commercial customers and is not intended for any discounts. Financial resources are limited, however, need very much, so that why we to have a wide range of hybrids that are trying to occupy the territory of social advertising. It is good if the tumors of these territory share the idea of social advertising, but very bad if they discriminate against. One of these is then a commercial advertising with the social discourse. Today, this technique is already so widely used.

Hypothesis: Advertising with social discourse aims to show company as social responsible one promote product using different cultural and behavioral stereotypes.

\section{"SCHEMAS" AND COMMERCIAL ADVERTISING WITH SOCIAL DISCOURSE}

It is no exaggeration to claim that today, most of our information, intellectual stimulation, and lifestyle models come from, or are related to, advertising images. This is an era in which advertising messages have moved away from describing the product in itself to focusing on the consumer of the product, creating product imagery with which the consumer can easy identify. Today, we can say that ads and commercials now offer the same kinds of promise and hope to which religions and social philosophies once held exclusive rights: security against the hazards of old age, better positions in life, popularity and personal prestige, social advancement, better health, and happiness. Marketers are pushing advertising's boundaries. Different companies have fueled the growth of so-called native content, creating both text and video that complement commercial messaging and encourage consumers to engage with it because it is more than an advertisement. Such advertising is conspicuously different from the conventional sort. In the best cases, it has editorial integrity and engages through relevance and value. But no matter how worthwhile your message, competing for attention simply by shouting louder across the proliferating array of media platforms is not sustainable strategy. 
"If human experience is a medium for advertising, how can marketers engage consumers there in way they will welcome?” (Rayport 2013). Rather than focusing first on communication strategy and marketing mix, they should begin by considering how consumers live their lives and under what circumstances they will prove receptive to messages in this domains.

For analyzing different advertisements had been selected as product ads and non-product ad. Since the aim of the study was to pull back the "ideological curtain" to see the power and ideology behind images, the chosen ads have more visual and less text. In other words, they communicate through images and pictures.

The advertisements are from Latvian media and brand promotion through social discourse.

Dimension of discourse and discourse analysis can be described in next positions:

(1) Text description: representing, relating, identifying positions for text analysis;

(2) Discursive practices (analysis/interpretation: position for processing);

(3) Social practices—social analysis/explanation.

So, we can call for the first dimension text analysis or description, for the second dimension processing analysis or interpretation, for the third dimension, it is the social analysis or explanation. All dimensions are interdependent and therefore it does not matter with which kind of analysis one starts.

\section{MATERIALS}

Four different advertisements, product ads, and non-product ads, had been selected for analyzing. Since the aim of the study was to pull back the "ideological curtain" to see the power and ideology behind images, the chosen ads have more visuals and less text. The chosen advertisements communicate through images and pictures. The advertisements are: "For a Real Childhood", "Help Put Your Baby in the
World”, "It Makes no Sense to Live Longer”, and "Motociclist's Summer".

\section{Sweets Manufacturer: Company "Laima"}

Here we have a picture of a baby in hammock (see Figure 1). The colors used in this ad are blue, white, and yellow. The color blue gives peace to the viewer, color yellow gives contrast, but color white behind the picture of baby attracts the viewers' attention and invites her/him to bay biscuits what lie below picture with baby. Above picture of baby is written in white "For a Real Childhood, Selga". Company "Laima" is the producer of this product (biscuit) ad and aims to show company as social responsible one, who care about children. The discourse of this "Laima" product could be considered as charity. Therefore, the viewer has the power to choose the biscuits or not. There is no force.

Firm "Elvi" (the Store Chain) Made

Campaign-"Help Put Your Baby in the World"

This is a picture of happy family: mother, father, and baby (see Figure 2). The company "Elvis" is the producer of this ad, there is no text because this is picture from booklet. The colors in this advertising is light, accent is on baby-pale bluish-green towel, man is kissing woman and she is kissing baby. The viewer is nearly too intimate with the family. On the booklet below is written: "Help put your baby in the world". This ad is considered to charity and try to solving a problem. As a result, the viewer has a power to be involved or not. This is no power above to force her/him.

\section{TV Channel-3 Realized Campaign "It Makes no Sense to Live Longer" About Abandoned Pets}

This is non-product ad (see Figure 3). As a result, its discourse is social responsibility to highlight the social problem. The colors in this advertisement are dark and 


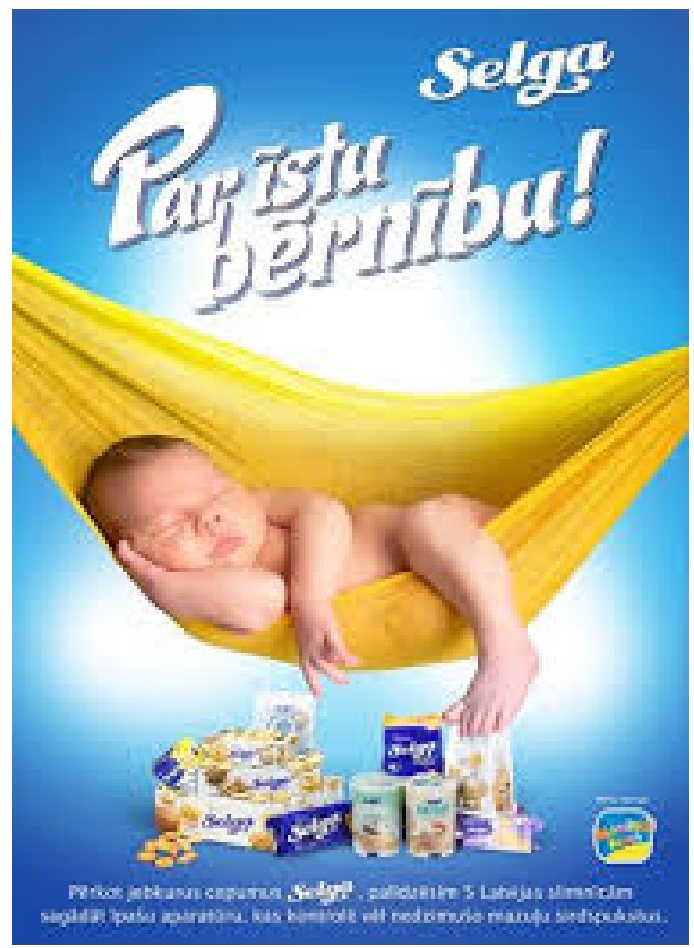

Figure 1. Advertisement "For a Real Childhood".

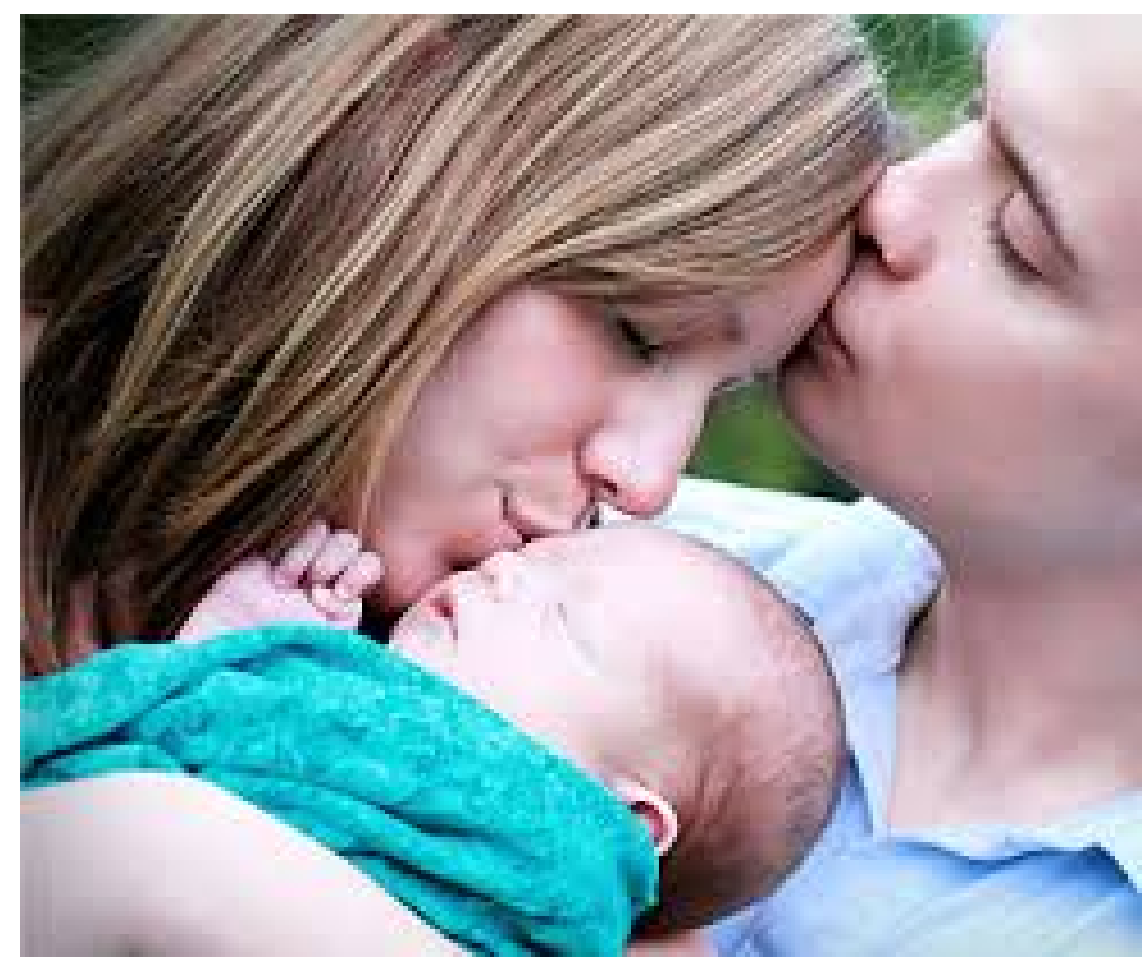

Figure 2. Advertisement "Help Put Your Baby in the World". 


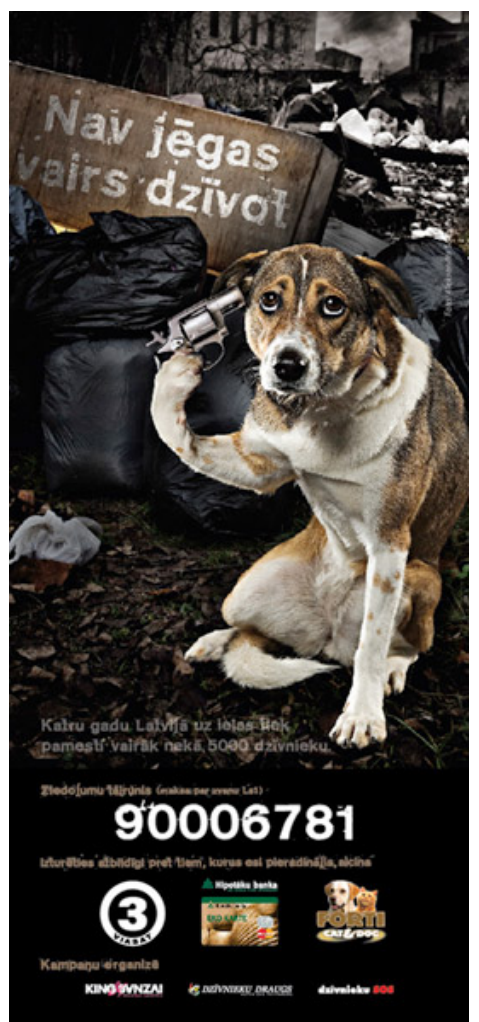

Figure 3. Advertisement "It Makes no Sense to Live Longer".

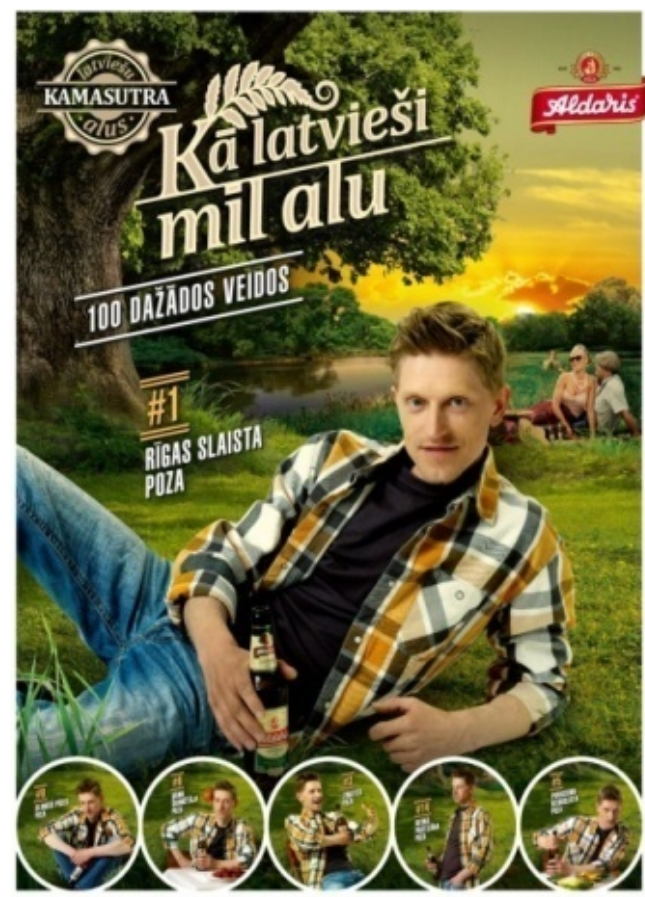

ALKOHOLA LIETOŠANAI IR NEGATTVA IETEKME

Figure 4. Advertisement "Motociclist's Summer". 
gloomy, only picture of a dog is more or less bright and the producer of this advertisement is TV channel-3. In the picture, a dog with gun on his head, behind on a box is written "It makes no sense to live longer". This ad is aiming to pay attention at problem. The eye level angel shows the power balance on the side of viewer. The viewer can feel the tragically results of not helping to pets. As a result, the viewer should obey the advertisement.

\section{Firm "Aldaris" (Beverage Manufacturer), the Campaign "How Latvians Love Beer"}

Here we have a picture of a young man, behind him, we can see a young couple (see Figure 4). A young man is in greens with bottle of beer into his hands. The colors used in this ad are light and pleasant, this bright colors attract the viewer's attention and encourage her/him to read the ad. This ad gives romantic sense to the viewer. On the corner of top of picture is the company's logo, in red and white color, on top of picture, above young man image, is written: "Latvian beer kamasutra. How Latvians love a beer in 100 different positions. No. 1 runabout of Riga”. The discourse of this ad is considered as lifestyle discourse, because it is reminder of tradition. Therefore, the viewer has the power to choose the beer or not, there is no force.

\section{CONCLUSIONS}

The purpose of this study was to analyze some advertisements, product ads, and non-product ads in order to see when the producers use their power to imply something to viewer. The analyses showed us that today, it is very modern to use social discourse for commercial ads. This technique allowed producers to make better relations between viewers (consumers) and company. In this case, we should use power in discourse as a form of social practice in various ways.
Power behind discourse describes the formation of the order of social practices, which are themselves shaped and constituted by power relation. By analyzing these advertisements and defining the position of the viewers, the followings were concluded.

The producers try to show that the viewer has the power to choose or not to choose something.

The ideology behind the images could be that powerful person should show her/his power; therefore, the powerless persons obey her/him. As a whole, it could be seen that producers use their power and ideology to change the behavior and thought of people. In case if people is aware of this fact, they can be more submissive, because they can imagine themselves in offered situations. This works as better as the narrative of situation is recognizable.

So, we can say that the socio-historical conditions that govern these processes of production and reception are containing. Interpretations of this power will be as effective as accurately we speak to the viewer. The hypothesis has been demonstrated.

\section{References}

Borns, L. E. and N. F. Ruso. 2001. Psihologija (Psychology). Riga, Latvia: Raka Ltd.

Carroll, A. B. 1991. "The Pyramid of Corporate Social Responsibility: Toward the Moral Management of Organizational Stakeholders.” Business Horizons July-August.

Cook, G. 1992. The Discurse of Advertising. London and NY: Routledge.

Fairclough. (1989) 1995. International Journal of Linguistics 4(4).

Ferrell, O. C. and M. D. Hartline. (2011) 2014. Marketing Strategy Text and Cases. 6th ed. South-Western Cengage Learning, Library of Congress Control.

Gee, J. P. (1999) 2005. An Introduction to Discourse Analysis-Theory and Method. 2nd ed. Routledge; Taylor and Francis.

Hall, S. 1973. Encoding and Decoding in the Television Discourse. Birmingham, England: Centre for Cultural Studies, University of Birmingham.

—. 1980. "Encoding/Decoding." In Culture, Media, 
Language. London: Hutchinson.

Hohlova, P. 2007. The Financial Ads. How It Produced in Great Britain. Moscow: Media Mir Ltd.

Kelly, A., K. Lawlor, and S. O’Donohoe. 2009. "Chapter 8-Encoding Advertisements: The Creative Perspective." In The Advertising and Consumer Culture Reader, edited by J. Turow and M. P. McAllister. New York: Routledge.

Kress, G. and T. Van Leeuwen. 1990. Reding Images. Victoria: Deakin Univesity Press.

1996. Reading Images: The Grammar of Visual Design. New York: Routledge.

Lebedev, A. 2003. Lebedev-Lubimov "Psychology of Advertising”. St. Petersburg, Moscow: Piter Ltd.

Maignan, I., T. L. Gonzales-Padron, G. Tomas, M. Hult, and O. C. Ferrell. N.d. Retrieved May 29, 2012 (http://www. cloudapps.com/selesforce-carbon-reporting).

Marieke de Mooji. 2014. Global Marketing and Advertising: Understanding Cultural Paradoxes. 4th ed. Sage Publications.

Nooyi, I. 2008. "The Responsible Company.” The Economist, March 31.

Pesockii, E. A. 2009. Reklamai motivācija potrebitelei (Advertising and Consumers Motivation). Moscow: Doshkow \& Co.

Rayport, J. F. 2013. Business Harvard Review, March.
Rayport, J. F. and B. J. Jaworski. 2004. Best Face Forward: Why Companies Must Improve Their Service Interfaces With Customers. Harvard Business School Press. Retrieved (http://Documents\%20and\%20Settings/Owner/My\%20Doc uments/Downloads/harvard_business_review_-_best_face_ forward.pdf).

Ries, A. and J. Trout. 2001. Positioning: The Battle for Your Mind. Mc Graw-Hill.

"Seven Steps to Strategy Making." 2013. Harald Business Review, September.

Scott, D. M. 2010. The New Rules of Marketing \& Pr. Wiley.

Van Dijk, T. A. 2006. "Discourse and Manipulation.” Discurse and Society 17(3):359-383.

Wodak, R. 1997. Gender and Discourse. Sage Publications.

- 1999. The Discursive Construction of National Identity. Edinburgh.

\section{Bio}

Aivars Gabriel Helde, Mg.art, lecturer, Department of Communication, Riga International School of Economics and Business Administration (RISEBA), Latvia; research fields: advertising and social marketing. 